Article

\title{
Research on the Transformation Path of the Green Intelligent Port: Outlining the Perspective of the Evolutionary Game "Government-Port-Third-Party Organization"
}

\author{
Bin Meng ${ }^{1}$, Haibo Kuang ${ }^{1}$, Erxuan Niu ${ }^{1}$, Jing $\mathrm{Li}^{2, *}$ and Zhenhui $\mathrm{Li}^{3}$ \\ 1 Collaborative Innovation Center for Transport Studies, Dalian Maritime University, Dalian 116026, China; \\ mengbinfly@163.com (B.M.); khb@dlmu.edu.cn (H.K.); mlzcdlmu@163.com (E.N.) \\ 2 School of International Trade and Economics, University of International Business and Economics, \\ Beijing 100029, China \\ 3 School of Economics and Management, Communication University of China, Beijing 100024, China; \\ lzhcuc@126.com \\ * Correspondence: jingli@uibe.edu.cn
}

Received: 23 August 2020; Accepted: 15 September 2020; Published: 30 September 2020

\begin{abstract}
While promoting the global economy and trade, ports impose serious pollution on the global ocean and atmosphere. Therefore, the development of ports is restrained by the policies and measures of governments and international organizations used to cope with climate change and environmental protection. With the development of information technology, the operation and expansion of ports is facing forms of green and intelligent reform. This research aims to link the development of green intelligent ports, government policies, and third-party organizations to find the most suitable evolutionary path for the development of green intelligent ports. This paper assumes that governments will push ports to transform into green intelligent ports from the perspective of benefiting long-term interests, that the goal of ports is to maximize their profits, and that third-party organizations will actively promote the development of green intelligent ports. Based on these assumptions, this paper has established an evolutionary game theory model of "government-port-third-party organization" regarding the development of green intelligent ports. The Jacobian matrix of the game theory system was constructed by using the replicator dynamic equation, and local stability analysis was performed to obtain the equilibrium stability point of the entire system. This research reveals the limitations of the development of green intelligent ports without government involvement and explores the ability of third-party organizations to promote the implementation of policies, confirming the role of government regulation and control in promoting the development of green intelligent ports. This paper may be helpful for the development of green intelligent ports in the future. The results show that: (1) The main factors affecting the choice of port strategy are the benefits of building a green intelligent port, the intensity of government regulation, and the quantitative influence of third-party evaluation results on the port strategy selection. (2) Government decision-making plays an important role in port transformation. If the relevant government chooses the wrong strategy, then the transformation of the port will be delayed. (3) Government regulation and control need to change with the change of the evolution stage. (4) Compared with the macro-control policies of the government, the influence of the third-party organization on the port is significantly smaller.
\end{abstract}

Keywords: green intelligent port; evolutionary game; government regulation; Lotka-Volterra model 


\section{Introduction}

Ports are an important part of the world's maritime logistics, and port logistics has become one of the key supporting industries for China's transportation development [1]. While ports improve economic efficiency, the energy consumption and waste emissions caused by their production operations and logistics as well as their transportation activities have caused serious problems for society and for the ecological environment [2]. A port generally aims to maximize its economic benefits, resulting in an excessive waste of resources. Without increasing costs to control the pollution caused by ship and port logistics activities, a port would likely have a negative impact on coastal cities and marine ecological environments, such as by causing air pollution [3], water pollution, and noise pollution. Since port development has been both restrained and encouraged by the policies and measures used by governments and international organizations to deal with climate change and environmental protection, it is therefore urgent to build green intelligent ports that can coordinate economic activities and environmental factors [4]. The 13th Five-Year Transport Plan released by the Ministry of Transport of the People's Republic of China in 2017 stated that building a green and low-carbon transport system would save resources and reduce pressure on the environment based on the characteristics of the transportation industry [5]. In 2018, the Ministry of Transport of the People's Republic of China issued a plan for deepening green port construction, which clearly stated that the country should accelerate the construction of an ecological civilization and a beautiful China, with structural reform of the supply chain as the main proposed method to achieve these goals, as well as further promoting green port construction [6].

In the new upcoming round of port reform, the strategic development plan for Chinese ports will be transformed from focusing on the control of resources to focusing on the rational and optimal allocation of resources. Green intelligent ports are the main development trend for ports throughout the world [7]. A green port adheres to a sustainable development path involving good environmental health, strong ecological protections, low energy consumption, and low pollution; this entails developing a new type of port that combines port development with environmental protection [8]. An intelligent port refers to the sustainable development of new ports with more intensive, efficient, convenient, safe, and green features that integrate related businesses and innovative management of ports using new generation technology. Ports that are both green and intelligent ports meet the requirements of sustainable development, high efficiency, and security in the new era. Therefore, green intelligent ports are the main development trend for ports all over the world. There is no conflict between green ports and intelligent ports, and they integrate well with each other in the development of new environmentally friendly energy systems and the construction of intelligent environmental protection systems for ports. Green intelligent ports involve the integration of safe and green development into the whole process of port planning, construction, and operation. It is necessary to strengthen the in-depth integration of modern information technology and the development of various fields of a port, promote the transformation of port development from being resource-driven to being intelligently innovation-driven, and promote the transformation of port development into a resource-saving and environmentally friendly venture. Finally, a new port era can be realized through a harmonious, unified, and coordinated development of ports and the environment.

In order to cope with future international port competition, the world's major ports are actively responding to the development of ports in the new era and carrying out green intelligent port transformations. The port of Singapore has proposed a strategic development goal of becoming part of the next generation of green intelligent ports, and has continued to invest funds in its ports, shipping, technology, services, energy usage, and other areas to encourage its stakeholders to implement additional green and intelligent actions. The port of Antwerp in Belgium aims to become the most sustainable port in Europe, and its future development will focus on energy, the environment, and becoming an intelligent port. The port of Los Angeles in the United States is the busiest seaport in the Western Hemisphere. It not only integrates advanced information technology to optimize port resource allocation, while developing and maintaining advanced and efficient port infrastructure, but also formulates green port policies to 
improve the port community environment. There are many pioneering practices in ecological protection, renewable energy utilization, and environmental management. The construction of green intelligent ports helps to integrate new information technology and intelligence and provides new opportunities and possibilities for the development of new formats of ports. By advancing the functionalization of port terminal operations, using advanced information technology, creating collaborative services in the logistics supply chain, building intelligent shipping, and pursuing the construction of ecological green ports, in the end, the goals of improving port handling efficiency, reducing customer business costs, trade liberalization and facilitation, creating integrated real-time monitoring of cargo-information-fund flows, developing unified industry business management standards, and implementing automation and intelligent comprehensive services can be achieved.

Most green intelligent port projects have the characteristics of energy conservation and environmental protection, strong social welfare, increased automation and specialization, etc. However, in the early stages, due to the large investments required, poor returns, long payback periods, and inconsistent understanding in the initial stage of the transformation, it is very difficult for ports to transform independently, and ports are often unwilling to bear the risk of transformation while experiencing earnings losses [9]. Under such circumstances, governments need to provide certain support and convey a sense of crisis to the ports in terms of policies, and to promote the transformation of ordinary ports into green intelligent ports in combination with third-party organizations [10]. However, due to information asymmetry and a lack of knowledge of changes in their industry, some ports tend to refuse to transform, a decision that is also affected by the transformation determination of the government, port, and third-party organizations. The transformation determination refers to the support of the government or the port for the development of green intelligent ports, which will affect the decisions made by both sides in the transformation process. If both sides have a low determination to make sure that the transformation occurs, then the possibility of port transformation will be reduced; since ports usually consider their interests to be their highest priority, governments and third-party organizations should therefore play the role of regulator to reshape those interests toward favoring transformation. In the process of port transformation, the interests of both governments and ports are affected. Because ports prioritize their interests under limited rationality, and governments and third-party organizations naturally assume less of the cost of port transformation, only when the interests of both sides are balanced can the transformation be a smooth process. For ports, understanding the significance of the transformation and reviewing their own strengths are conducive to their responses to government regulation and control. For governments, it is better to promote the construction of green intelligent ports by controlling regulations and control intensity in the process of port transformation. Only through mutual cooperation and coordination can the two sides achieve coordinated development in the process of green intelligent port transformation, give full play to government functions, and further promote the construction of green intelligent ports. With the continuous enrichment of third-party organizations, the evaluation and supervision of ports will become more and more effective, and this could be coordinated with governments to effectively promote the development of green intelligent ports. Governments have promulgated relevant policies to promote the construction of green intelligent ports, such as reducing related taxes on green intelligent ports, granting subsidies to ports that meet standards, imposing penalties on ports that fail to meet standards, etc. The influence of third-party organizations on ports is also gradually increasing. However, most of the existing studies focus on the policy level, while there is a lack of empirical analysis and discussion confirming the relationship between the three factions, and lack of focus on changes the market competitiveness of ports and how this is affected by governments and ports through policy approaches; finally, there is a lack of analysis of the measurement of optimal government regulation and control intensity. Therefore, based on the evolutionary game theory, this paper explores the evolutionary path of green intelligent port construction under the regulation of governments and third-party organizations and reveals the role of regulation by governments and third-party organizations in promoting the development of green intelligent ports. 


\section{Literature Review}

Port activities are expected to increase in the near future as a consequence of growing maritime traffic and of trade globalization [11]. However, shipping is becoming a significant source of air pollution, particularly in cities near major ports [12]. Ships using auxiliary power generators when docking can cause serious air pollution and thus pose a threat to port cities [13]. Environmental problems that seriously affect both natural systems and the social development of human beings have drawn extensive attention from governing authorities all around the world and have become an urgent issue to be addressed [14]. The global environmental impact of pollution from international shipping is increasing, despite regulatory measures to curb its rise [15].

Ports are durable coastal assets that exist for a very long time, so their environmental impacts are long-lasting. Pollution comes from various sources including ships, terminals, and port hinterland transportation [16]. Now, sustainability agendas are challenging port authorities around the world to find ways to use port assets more efficiently and productively in economic, social, as well as environmental terms [17]. Going green is a trend for seaports all over the world [18].

Ports have considerable potential to promote environmental upgrades but have so far achieved only partial success in this regard [19]. Therefore, ports face increasing pressure to become more environmentally and socially conscious [20]. Now, a recent survey showed that $90 \%$ of respondent ports stated that they have an environmental policy and $94 \%$ of ports have designated environmental personnel [21]. However, the findings also showed that a significant number of ports are still not engaging in green marketing at all or in a very limited manner [22]. So, Segui et al. [23] considered that there is room for improvement.

Developing a green intelligent port is a significant form of progress in the specific applications of energy conservation and emissions reduction, as well as intelligent technologies in global ports and maritime shipping sectors [24]. These applications would help increase the quality of human life. As a result, environmental sustainability in the port industry is a growing priority for port authorities, policy makers, port users, and local communities [25]. However, without customer demand, subsidies, or other incentives, port environmental practices will likely always be constricted by economic and operational considerations [26]. For the process of implementing environmental policies, Woo et al. [27] found that negative effects increase faster than positive effects of implementation in the short term, while positive effects become larger than negative effects in the midterm and long term. Therefore, in the process of port transformation, government policy support is needed to facilitate increased short-term benefits or motivations to pursue necessary initial changes. After the implementation of government policies, ports can become mature in implementing environmental standards and regulations [28]. Green intelligent port policies need to be interlinked covering social, economic, and environmental dimensions and utilizing an integrated approach in order to realize maximum potential and strengthen green port processes [29]. Research shows that the implementation of effective incentives has had a big effect on a port's satisfaction toward reform [30]. At the same time, research results also show that port-based incentives can help drive the uptake of green technologies [31]. The factors that affect green port policies have important theoretical and practical significance in the study of green port construction [32].

Game theory has been used by many experts and scholars for solving many problems involving mutual benefit. An example is the game of profit between the port user's surplus and that of the terminal operator [33]. A game theory approach has been used to model the competition between several port authorities, and it was used to determine how to attract additional ships while maximizing the interests of port authorities [34]. Moreover, the game theory model also can be used to prove that bank cooperation can effectively increase profits and reduce costs [35]. A game theory model can be implemented between a government and landholders to improve the water retention capacity of soil [36], or a cooperative game between a natural gas network and its market while considering externalities [37]. Game theory is usually used to solve conflicts of interests between two sides and seek the balance point between them. 
Although existing research has made great progress, there are still two drawbacks: (1) At present, most research is still confined to macro policy suggestions for green intelligent port construction, but the question of how these policy suggestions affect port transformations is a new research breakthrough. In China, the concept of green intelligent ports has been examined for a short period of time. Most ports have no clear awareness of the construction of green intelligent ports, and most of the existing research interprets only previous successful cases of green intelligent port construction, from which we can obtain useful policy suggestions related to the construction and development of green intelligent ports. Few papers study port transformation after the implementation of policies encouraging this shift, and the analysis of the relationship between the construction of green intelligent ports and government regulation and control is not deep enough. (2) In the construction process of green intelligent ports, there are bound to be collisions with standard ports that generate sparks. The changes in market competitiveness of the two sides and a government's optimal regulation and control intensity under certain policy inclinations are also worth studying. A government's supervision of ports generally continues during the period of construction and development of general ports, and there are no reward or punishment measures for port development. When green intelligent port construction policies are introduced, they are bound to conflict with the normal development of ports. The market competitiveness of both sides in conflict must be changed dramatically, and a government's optimal levels of regulation and control intensity need further study.

Aimed at focusing on the above shortcomings and based on the limited rationality of decision makers, this paper uses evolutionary game models and dynamic game equations to study the decision-making of green intelligent port transformations under the control of government and third-party organizations, analyzes the impact of government regulation and control on the market competitiveness of green intelligent port construction and general port construction through diffusion models, and finally uses simulations to prove the authenticity of the results obtained in the paper. Compared with the existing research, when considering several aspects such as the government subsidies, port fines, rewards from superiors, and third-party evaluation, this paper determines that governments, ports, and third-party organizations should make efforts during the construction of green intelligent ports to obtain a revenue matrix including all three sides. By using the replication dynamic equation and Jacobian matrix, the stability strategy points of the three parties in the game (a government, a port, and third-party organizations) are calculated, and then the evolution path of the green intelligent port under the regulation of a government and third-party organizations is concluded. This paper describes the restrictive relationship between the three in the transformation of green intelligent ports, explores the main driving factors for the construction of green intelligent ports, and makes up for the deficiencies of the existing research that focus on macro policy regulation and lack of government policies influencing the transformation path of ports. At the same time, this paper establishes a diffusion model for green intelligent ports to measure the relationship between government regulation and green intelligent port transformation with the aid of the Lotka-Volterra model. These all confirm the role of government regulation in promoting the development of green intelligent ports and help governments to perform their supervisory functions more comprehensively and understand the transformation process of green intelligent ports.

\section{Model Construction}

\subsection{Symbol Description}

This model set ups two evolutionary game players: the government and the port, both of which have the characteristics of bounded rationality. Parameters such as government subsidies, fines, and green benefits are added to study the evolution rules under different strategies of each player. The local government has two strategies: $G=$ \{conduct green intelligent port supervision, do not conduct green intelligent port supervision\}. There are two strategies for the port: $H=$ \{increase investment in green intelligent port construction, do not increase investment in green intelligent port 
construction\}. The third-party organization has two strategies: $T=$ \{conduct green intelligent port standard evaluation, do not conduct green intelligent port standard evaluation\}. The probability of a third-party organization choosing "do conduct green intelligent port standard evaluation" is $z$, and the probability of choosing "do not conduct green intelligent port standard evaluation" is 1-z; The probability of a local government choosing "do conduct green intelligent port supervision" is $y$, and the probability of choosing "do not conduct green intelligent port supervision" is 1-y. The probability of a port choosing the strategy of "do increase investment in green intelligent construction" is $x$, and the probability of a port choosing "do not increase investment in green intelligent construction" is 1-x.

To construct a game model, it is necessary to clarify the variables that affect a government and port's decision-making. For the choice of port variables, Song used port management fees in a study of port competition games [38]. Talley et al. [39] believes that port costs mainly involve daily maintenance and port technology investment. Chang included port performance income in an analysis of port emission transformation [40]. For the choice of government variables, government subsidies are often regarded as the main influencing factors associated with government regulation [41-43] in the game between the government and enterprises. Xi additionally used a government supervision cost construction model [44]. Jiang introduced non-cooperative fines and external benefits as variables in a game of conflict of interest between a government and airlines, and introduced third-party organizations that could assist with the implementation of government policies [45]. Gao added a superior government reward as a variable in the evolutionary game to motivate a port to evaluate government policies in certain ways and suggested that superior central governments give third-party organizations subsidies to supervise the construction and development of local governments and ports [46]. Based on these previous research results, this current research summarizes a set of parameters applicable to the game model of this paper, and the specific parameters are as follows.

When a port strengthens its inclination toward the construction of a green intelligent port, the input cost is $c_{p 1}$, which includes the logistics infrastructure configuration input and green intelligent port investment; that is, this input cost is the cost to continuously expand the port's infrastructure configuration, then to step up investment in energy conservation and emission reduction projects, major port equipment and processes, logistics parks, and comprehensive information systems. The input cost for a scenario without investment in green intelligent port construction is $c_{p 2}$; this is the input cost to improve and expand port infrastructure only. The energy consumption control and pollution treatment cost of a port with an investment in green intelligent port construction is $z_{p 1}$. For example, energy saving and emission reduction facilities are used to control the energy consumption per unit throughput and improve the comprehensive utilization of wastewater and waste. The cost of energy consumption control and pollution treatment without increasing investment in green intelligent port construction is $z_{p 2}$; here, the original governance mode of the port is used to control pollution. The performance benefit from an investment in green intelligent port construction is $s_{p 1}$; that is, the green transportation efficiency, green storage, and loading and unloading level, logistics collection and distribution capacity, and economic benefit are improved by strengthening the construction of green intelligent ports. The performance benefit of not increasing the investment in green intelligent port construction is $s_{p 2}$. Suppose that $e$ represents the comprehensive loss when a third-party organization evaluated the port and it failed to meet necessary standards. Also suppose that $m_{3}$ represents the port's comprehensive quantitative income, which is increased along with that port's social reputation when third-party organizations conduct green intelligent port standard evaluations and when the port increases its green intelligent port construction investment.

$s_{p 2}{ }^{-} c_{p 2}{ }^{-} z_{p 2}$ means a port's performance gains, minus construction costs and governance costs when the port chooses not to increase investment in green intelligent port construction. $s_{p 1}{ }^{-} c_{p 1}{ }^{-} z_{p 1}$ represents a port's performance gains, minus construction costs and governance costs when the port chooses to increase investment in green intelligent port construction. Let $\lambda_{1}$ be equal to $s_{p 1}{ }^{-} c_{p 1}{ }^{-} z_{p 1}$ and $\lambda_{2}$ be equal to $s_{p 2}{ }^{-} c_{p 2}{ }^{-} z_{p 2}$. Hence, $\lambda_{2}-\lambda_{1}$ is the difference in the transformation income before and after a port increases green intelligent port construction investment, which, whether positive or 
negative, is affected by the maturity of the port's green intelligent port development and its market's acceptance of green intelligent ports.

According to government strategies set in the evolutionary game model, it can be seen that a government mainly has two choices: "conduct green intelligent port supervision" and "do not conduct green intelligent port supervision". If a government chooses to supervise, it then needs to carry out certain supervision measures on ports and third-party organizations. Hence, the cost of government supervision is $c_{g}$. If the government chooses to supervise and a port has progressed in its construction of a green intelligent port, then the government will grant certain policy subsidies $b$ to the port to encourage the port to increase its investment in a green intelligent port and in innovations in energy conservation and emissions reduction projects. In addition, after the port strengthens its construction of a green intelligent port, it will also obtain certain green performance benefits and rewards $s_{g 1}$ from higher-level government and its local government. If a government does not conduct a green intelligent port evaluation, then the gain is $s_{g_{2}}$. If the government chooses to carry out the evaluation but the port does not progress in the construction of a green intelligent port, then the government will take punitive measures based on the problems of pollution emissions and energy consumption management, by imposing a fine of $p$. The governance cost for the government due to the port's failure to progress in the construction of a green intelligent port is $z_{g} . m_{1}$ represents the subsidy given by the government when a third-party organization performs a evaluation of the port.

When third-party organizations choose to evaluate ports, they need to evaluate the input and output of green intelligent ports in accordance with the set evaluation index system to judge the development level of the green intelligent port, including the green intelligent port infrastructure, port energy consumption, and the evaluation of pollution control standards, port logistics development capabilities, the port economy, the hinterland economy, and the port's social contribution, which will incur $c_{f}$ evaluation costs. Because the third-party organization is a nonprofit organization, in addition to what it gets from the government, it also has a certain amount of funding that is represented by the parameter $s_{f}$. When the third-party organization conducts an evaluation, the government supervises it, and the port meets the government's standards, the government rewards the third-party organization with the benefit $m_{2}$; when the third-party organization does not conduct an evaluation and the government determines that the port does not meet its standards, then government will reduce the autonomy of that port by reducing funding to it, which is represented by the parameter $r$.

The hypothesis arrangement of each parameter is shown in Table 1:

Table 1. Interpretation of each parameter of the evolutionary game model.

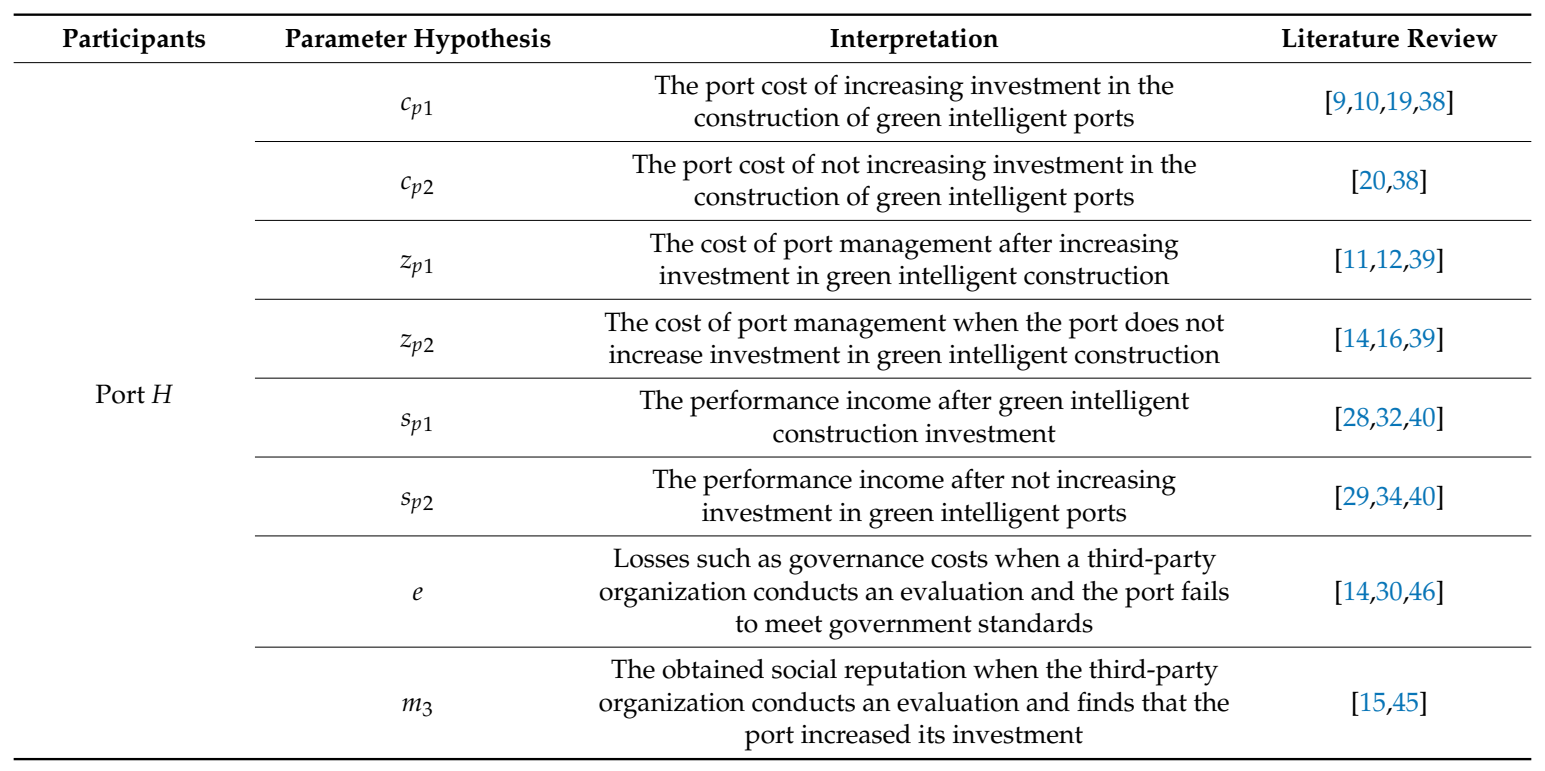


Table 1. Cont.

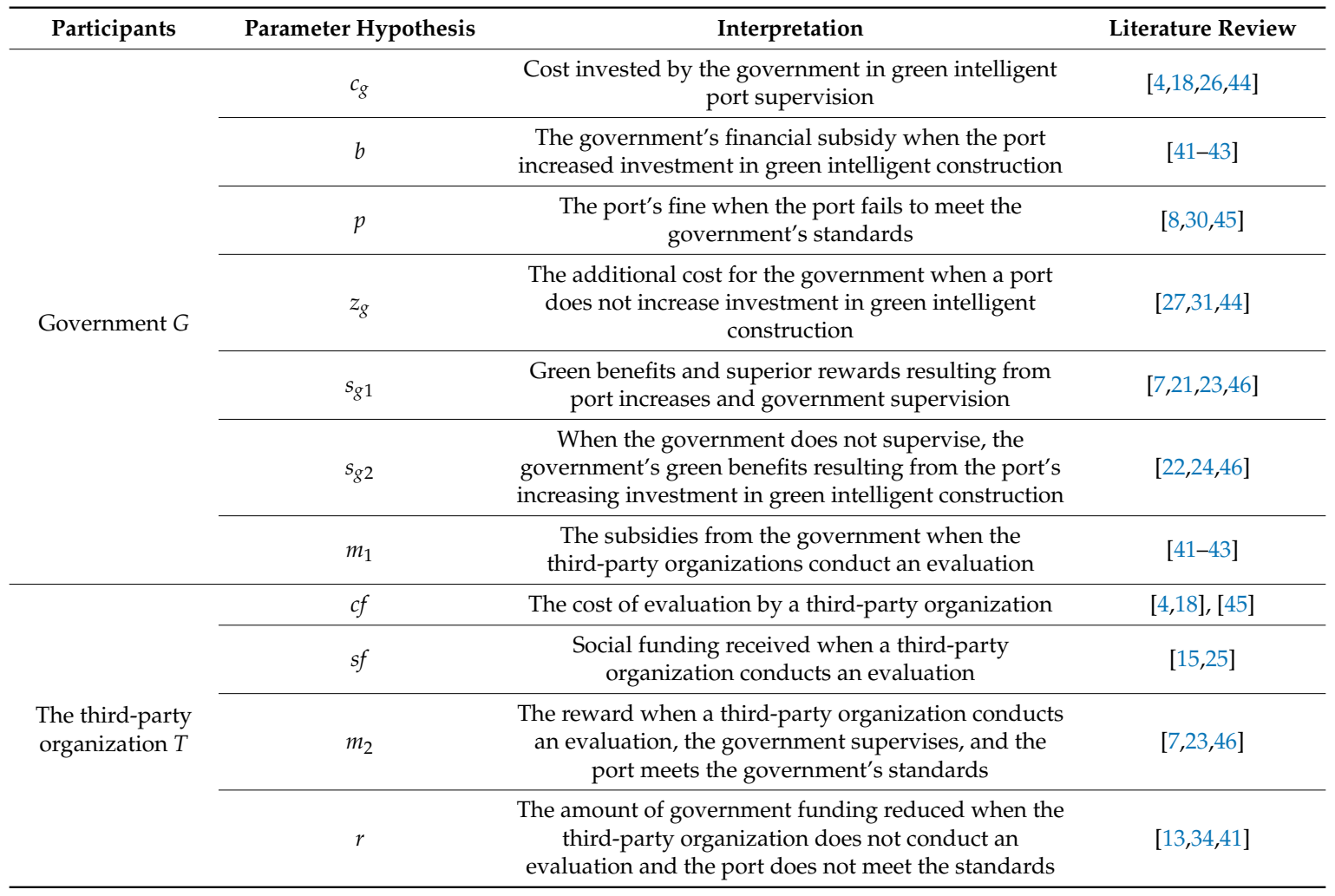

The parameters and basic assumptions in the diffusion model can be explained as follows:

1. Assume that the initial period of the diffusion model is the same as that of the evolutionary game model.

2. Suppose that the participants in the diffusion model are the same as the participants in the evolutionary game model, that is, the government and the port.

3. The definitions of $b, p, c_{p 1}$, and $c_{p 2}$ parameters in the diffusion model are the same as those in the evolutionary game, which represent the policy subsidy, reward, or punishment measures when the government evaluates the port. In this paper, these two parameters are also the main external influencing factors for the port to choose green intelligent port construction. In the formula, $\alpha_{1}$ represents the proportion of government subsidies in the total cost of green intelligent port construction, which is the government subsidy coefficient. $\alpha_{2}$ represents the proportion of the government penalty in the total cost of green intelligent port construction, which is the government penalty coefficient. The changes of the government subsidy coefficient and the punishment coefficient affect the diffusion rate and comprehensive development level of green intelligent port construction.

4. $h_{1}(t)$ and $h_{2}(t)$ in the diffusion model represent the number of port market investors that choose to increase the construction of green intelligent ports at time $t$ and the number of port market investors that do not choose to strengthen the construction of green intelligent ports, respectively.

5. $N_{1}$ and $N_{2}$ in the diffusion model respectively represent the maximum market capacity of the two port types, such as the maximum capacity of port throughput, logistics collection, distribution capacity, etc.

6. Assuming that there is a competitive and cooperative relationship between the two types of ports in the diffusion model, parameters $\gamma_{12}=\frac{N_{2}}{N_{1}}$ and $\gamma_{21}=\frac{N_{1}}{N_{2}}$ respectively represent the coefficients of competition and cooperation between ports. This means they are the inhibition coefficient of general ports for increasing the construction of green intelligent ports, and the 
substitution coefficient of innovative ports for general ports. These coefficients are affected by the market for green intelligent ports, acceptance of the intelligent port concept, the construction cost, the pollution control cost of green intelligent ports, the improvement of green intelligent port technology, innovative investment in energy conservation and emission reduction projects, port logistics performance and development potential, etc.

7. Assuming that the internal competition coefficient $\beta_{i}$ of the population in the diffusion model is 1 , the influence of the internal competitive relationship of the port on the result is not considered.

8. The diffusion model is not affected by other diffusion factors in the cycle.

\subsection{The Construction of the Tripartite Evolutionary Game Model}

After setting the strategies and parameters of each subject in the tripartite evolutionary game model, the profit matrix of each party under different strategies can be found through analysis, as shown in Tables 2-4.

Table 2. The income matrix of $(z)$ when the third-party organization conducts an evaluation.

\begin{tabular}{cccc}
\hline \multirow{2}{*}{ Participants and Strategies of the Game } & \begin{tabular}{c} 
Port $\boldsymbol{H}$ \\
\cline { 2 - 4 }
\end{tabular} & $\begin{array}{c}\text { Increase in Green } \\
\text { Intelligent Investment }(\boldsymbol{x})\end{array}$ & $\begin{array}{c}\text { No Increase in Green } \\
\text { Intelligent Investment (1-x) }\end{array}$ \\
\hline \multirow{2}{*}{ Government $G$} & $\begin{array}{c}\text { Adopt supervised } \\
\text { behavior }(y)\end{array}$ & $\begin{array}{c}\lambda_{1}+b+m_{3},-c_{g}+s_{g 1}{ }^{-} b- \\
m_{1}-m_{2}\end{array}$ & $\lambda_{2}{ }^{-} p-e,-c_{g}-z_{g}+p-m_{1}$ \\
\cline { 2 - 4 } & $\begin{array}{c}\text { Adopt unsupervised } \\
\text { behavior }(1-y)\end{array}$ & $\lambda_{1}+m_{3}, s_{g 2}{ }^{-} m_{1}$ & $\lambda_{2}{ }^{-} e_{,}-z_{g}{ }^{-} m_{1}$ \\
\hline
\end{tabular}

Table 3. The income matrix of $(1-z)$ when the third-party organization does not conduct an evaluation.

\begin{tabular}{cccc}
\hline \multirow{2}{*}{ Participants and Strategies of the Game } & \multicolumn{2}{c}{ Port $\boldsymbol{H}$} \\
\cline { 2 - 4 } & $\begin{array}{c}\text { Increase in Green } \\
\text { Intelligent Investment }(\boldsymbol{x})\end{array}$ & $\begin{array}{c}\text { No Increase in Green } \\
\text { Intelligent Investment (1-x) }\end{array}$ \\
\hline \multirow{2}{*}{ Government $G$} & $\begin{array}{c}\text { Adopt supervised } \\
\text { behavior }(y)\end{array}$ & $\lambda_{1}+b,-c_{g}+s_{g 1}-b$ & $\lambda_{2}-p,-c_{g}{ }^{-} z_{g}+p+r$ \\
\cline { 2 - 4 } & $\begin{array}{c}\text { Adopt unsupervised } \\
\text { behavior }(1-y)\end{array}$ & $\lambda_{1}, s_{g 2}$ & $\lambda_{2},-z_{g}$ \\
\hline
\end{tabular}

Table 4. The income matrix of third-party organizations under different strategies adopted by the port and the government.

\begin{tabular}{cccc}
\hline \multirow{2}{*}{$\begin{array}{c}\text { Participants and } \\
\text { Strategies of the Game }\end{array}$} & \multicolumn{3}{c}{ Third-Party Organization $T$} \\
\cline { 2 - 4 } & \multicolumn{2}{c}{ Conducts Evaluation $(z)$} & $\begin{array}{c}\text { Does not Conduct } \\
\text { Evaluation (1-z) }\end{array}$ \\
\hline \multirow{3}{*}{$\begin{array}{c}\text { Port } \boldsymbol{H} \\
\text { Government } \boldsymbol{G}\end{array}$} & Increase, supervise &,,$---c_{f}+m_{1}+s_{f}+m_{2}$ &,,-- 0 \\
\cline { 2 - 4 } & Increase, not supervise &,,$---c_{f}+m_{1}+s_{f}$ &,,-- 0 \\
\cline { 2 - 4 } & Not increase, supervise &,,$---c_{f}+m_{1}+s_{f}$ &,,$---r$ \\
\cline { 2 - 4 } & Not increase, not supervise &,,$---c_{f}+m_{1}+s_{f}$ &,,-- 0 \\
\hline
\end{tabular}

In the analysis process of the above game model, it can be concluded that there is a certain relationship between government monitoring and the development of green intelligent ports. We can use the Lotka-Volterra model to further analyze the relationship between the two sides. The Lotka-Volterra model was originally developed from the logistic model of population ecology. The purpose of the Lotka-Volterra model is to study the competitive and cooperative relationship between different populations in the ecosystem; that is, the relationship between different populations 
and within different populations in the limited resource environment. Since then, the model has been applied to more industrial fields to study innovation diffusion, evolution, and competition.

The original state of the Lotka-Volterra model and the logistic model are shown in Equation (1):

$$
\left\{\begin{array}{l}
\frac{d h_{1}(t)}{d t}=\alpha_{1} h_{1}\left(1-\frac{h_{1}}{N_{1}}-\frac{\gamma_{12} h_{2}}{N_{1}}\right) \\
\frac{d h_{2}(t)}{d t}=\alpha_{2} h_{2}\left(1-\frac{h_{2}}{N_{2}}-\frac{\gamma_{21} h_{1}}{N_{2}}\right)
\end{array}\right.
$$

\subsection{Construction of the Port Diffusion Model}

For a single port to increase its utilization of green intelligent logistics [47], its market growth rate must conform to a logistic model shown in Equation (2):

$$
\frac{d h_{1}(t)}{d t}=\frac{b}{c_{p 1}+z_{p 1}} h_{1} \frac{N_{1}-h_{1}}{N_{1}}
$$

At the same time, the port with basic green intelligent logistics construction also has an impact on it. Equation (2) changes to Equation (3).

$$
\frac{d h_{1}(t)}{d t}=\frac{b}{c_{p 1}+z_{p 1}} h_{1} \frac{N_{1}-h_{1}}{N_{1}}-\frac{b}{c_{p 1}+z_{p 1}} h_{1} \frac{\gamma_{12} h_{2}}{N_{1}}=\frac{b}{c_{p 1}+z_{p 1}} h_{1}\left(1-\frac{h_{1}}{N_{1}}-\frac{\gamma_{12} h_{2}}{N_{1}}\right)
$$

Therefore, the logistics of the green intelligent port diffusion model in this paper can be constructed as shown in Equation (4).

$$
\left\{\begin{array}{l}
\frac{d h_{1}(t)}{d t}=\frac{b}{c_{p 1}+z_{p 1}} h_{1}\left(1-\frac{h_{1}}{N_{1}}-\frac{\gamma_{12} h_{2}}{N_{1}}\right) \\
\frac{d h_{2}(t)}{d t}=\frac{p}{c_{p 1}+z_{p 1}} h_{2}\left(1-\frac{h_{2}}{N_{2}}-\frac{\gamma_{21} h_{1}}{N_{2}}\right)
\end{array}\right.
$$

Let $a_{1}=\frac{b}{c_{p 1}+z_{p 1}}, a_{2}=\frac{p}{c_{p 1}+z_{p 1}}$, which allows simplification into Equation (5).

$$
\left\{\begin{array}{l}
\frac{d h_{1}(t)}{d t}=\alpha_{1} h_{1}\left(1-\frac{h_{1}}{N_{1}}-\frac{\gamma_{12} h_{2}}{N_{1}}\right) \\
\frac{d h_{2}(t)}{d t}=\alpha_{2} h_{2}\left(1-\frac{h_{2}}{N_{2}}-\frac{\gamma_{21} h_{1}}{N_{2}}\right)
\end{array}\right.
$$

Equations (2)-(5) show the transforming process from the logistic model to the green intelligent port diffusion model. The development scale of green intelligent ports in the results indicates the acceptance of green intelligent port construction, rather than the final evolutionary result.

\section{Model Analysis}

\subsection{The Solution of the Replicator Dynamic Equation for Three Sides}

(1) The solution of the replicator dynamic equation for the port:

Let $H_{11}$ be the expected return function when adopting an increase in the investment in the construction of a green intelligent port, $H_{12}$ is the expected return function when adopting a non-increasing investment in the construction of a green intelligent port. $\bar{H}$ is the port average expected revenue, as shown in Equation (6). The replicator dynamic equation of the port is shown in Equation (7).

$$
\begin{gathered}
\left\{\begin{array}{c}
H_{11}=y z\left(\lambda_{1}+b+m_{3}\right)+y(1-z)\left(\lambda_{1}+b\right)+z(1-y)\left(\lambda_{1}+m_{3}\right)+(1-y)(1-z) \lambda_{1} \\
H_{12}=y z\left(\lambda_{2}-p-e\right)+y(1-z)\left(\lambda_{2}-p\right)+z(1-y)\left(\lambda_{2}-e\right)+(1-y)(1-z) \lambda_{2} \\
\bar{H}=x H_{11}+(1-x) H_{12}
\end{array},\right. \\
F(x)=\frac{d x}{d t}=x\left(H_{11}-\bar{H}\right)=x(1-x)\left[y(b+p)+z\left(m_{3}+e\right)+\left(\lambda_{1}-\lambda_{2}\right)\right]
\end{gathered}
$$

(2) The solution of the replicator dynamic equation for the government: 
The strategies for the government in the tripartite game are "adopt green intelligent port supervision" and "do not adopt green intelligent port supervision". Let $G_{21}$ be the expected return function of the government when adopting green intelligent port supervision, and $G_{22}$ be the expected return function of the government when not adopting green intelligent port supervision. $\bar{G}$ is the average government expected return, as shown in Equation (8). The replicator dynamic equation for the government is shown in Equation (9)

$$
\begin{aligned}
& \left\{\begin{array}{l}
G_{11}=x z\left(-c_{g}-b+s_{g 1}-m_{1}-m_{2}\right)+x(1-z)\left(-c_{g}-b+s_{g 1}\right) \\
+z(1-x)\left(-c_{g}-z_{g}+p-m_{1}\right)+(1-x)(1-z)\left(-c_{g}-z_{g}+p+r\right) \\
G_{12}=x z\left(s_{g 2}-m_{1}\right)+x(1-z) s_{g 2}+z(1-x)\left(-z_{g}-m_{1}\right)+(1-x)(1-z)\left(-z_{g}\right) \\
\bar{G}=y G_{11}+(1-y) G_{12}
\end{array}\right. \\
& F(y)=\frac{d y}{d t}=y\left(G_{21}-\bar{G}\right)=y(1-y)\left[x\left(s_{g 1}-s_{g 2}-b-p-r\right)+x z\left(r-m_{2}\right)-z r+p+r-c_{g}\right]
\end{aligned}
$$

(3) The solution of the replicator dynamic equation for the third-party organization:

The strategies for the third-party organization in the tripartite evolution game are "adopt green intelligent port standard evaluation" and "do not adopt green intelligent port standard evaluation". Let $T_{31}$ be the expected revenue function of the third-party organization when adopting green intelligent port standard evaluations, and $T_{32}$ be the expected revenue function of the third-party organization when not adopting green intelligent port standard evaluation. $\bar{T}$ is the average expected revenue of third-party organizations, as shown in Equation (10). The replicator dynamic equation of the third-party organization is shown in Equation (11).

$$
\begin{gathered}
\left\{\begin{array}{l}
T_{11}=x y\left(-c_{f}+s_{f}+m_{1}+m_{2}\right)+x(1-y)\left(-c_{f}+s_{f}+m_{1}\right) \\
+y(1-x)\left(-c_{f}+s_{f}+m_{1}\right)+(1-x)(1-y)\left(-c_{f}+s_{f}+m_{1}\right) \\
T_{12}=y(1-x)(-r) \\
\bar{T}=z T_{11}+(1-z) T_{12}
\end{array}\right. \\
F(z)=\frac{d z}{d t}=z\left(T_{11}-\bar{T}\right)=z(1-z)\left[x y\left(m_{2}-r\right)+y r+s_{f}+m_{1}-c_{f}\right]
\end{gathered}
$$

\subsection{The solution of Equilibrium Point of the Tripartite Evolutionary Game}

Equations (7), (9), and (11) are the replicator dynamic equations of three sides. The equilibrium points of the tripartite evolutionary game can be discussed by solving the equations. All equilibrium points can be obtained through simultaneous equations $F(x), F(y), F(z)$, as shown in Equation (12).

$$
\left\{\begin{array}{l}
F(x)=x(1-x)\left[y(b+p)+z\left(m_{3}+e\right)+\left(\lambda_{1}-\lambda_{2}\right)\right]=0 \\
F(y)=y(1-y)\left[x\left(s_{g 1}-s_{g 2}-b-p-r\right)+x z\left(r-m_{2}\right)-z r+p+r-c_{g}\right]=0 \\
F(z)=z(1-z)\left[x y\left(m_{2}-r\right)+y r+s_{f}+m_{1}-c_{f}\right]=0
\end{array}\right.
$$

By solving the simultaneous equations, some equilibrium points can be obtained, which are $B_{1}(0,0,0), B_{2}(0,0,1), B_{3}(0,1,0), B_{4}(0,1,1), B_{5}(1,0,0), B_{6}(1,0,1), B_{7}(1,1,0), B_{8}(1,1,1)$, and $B_{9}\left(x^{*}\right.$, $\left.y^{*}, z^{*}\right)$. For these equations, the $\mathrm{x}, \mathrm{y}$, and $\mathrm{z}$ values satisfy the equilibrium points $B_{1} \sim B_{8}$, which are $0 \leq x \leq 1,0 \leq y \leq 1,0 \leq \mathrm{z} \leq 1$. This value condition also constitutes the boundary of the equilibrium solution of the tripartite evolutionary game. Under this value condition, the equilibrium point $B_{9}$ exists. By solving Equation (13), $x^{*}, y^{*}$, and $z^{*}$ can be obtained. The results are shown in Equation (14).

$$
\left\{\begin{array}{l}
y(b+p)+z\left(m_{3}+e\right)+\left(\lambda_{1}-\lambda_{2}\right)=0 \\
x\left(s_{g 1}-s_{g 2}-b-p-r\right)+x z\left(r-m_{2}\right)-z r+p+r-c_{g}=0 \\
x y\left(m_{2}-r\right)+y r+s_{f}+m_{1}-c_{f}=0
\end{array}\right.
$$




$$
\left\{\begin{array}{rl}
x & =\frac{z r-r-p+c_{g}}{s_{g 1}-s_{g 2}-b-p-r+z\left(r-m_{2}\right)} \\
y & =\frac{-z\left(m_{3}+e\right)-\left(\lambda_{1}-\lambda_{2}\right)}{b+p} \\
z & =\frac{c_{g}-p-r-x\left(s_{g 1}-s_{g 2}-b-p-r\right)}{x\left(r-m_{2}\right)-r}
\end{array} .\right.
$$

By analyzing Equation (14), it can be seen that the stability of the entire evolutionary system is related to the difference of green intelligent port investment returns, fines, and government subsidies to the port, grants and awards to the third-party organization, government regulatory costs, and the positive social reputation brought to the port by the third-party organizations. In addition, the stable state of the port in the evolutionary system is related to the fluctuation probability $y$ of the government choosing the supervision strategy and the probability $z$ of the third-party organization choosing the evaluation strategy. The stable state of the government in the evolutionary system is related to the fluctuation probability $x$ of a port choosing to increase investment in green intelligent port construction and the probability $z$ of the third-party organization selecting an evaluation strategy. The stable state of the third-party organization in the evolutionary system is related to the fluctuation probability $x$ of the port selecting to increase investment in green intelligent port construction and the probability $y$ of the government selecting the supervision strategy. Therefore, the robust state for the equilibrium of the tripartite evolutionary game in the change process of $x, y, z$ evolution probability needs to be further discussed through numerical simulation.

When derivation of the replicator dynamic equation of the three-sided system continues, Equation (15) can be obtained. According to the theory of evolutionary game stability strategy, when the equilibrium point is substituted into the formula, it needs to satisfy $F^{\prime}(\mathrm{x})<0, F^{\prime}(\mathrm{y})<0, F^{\prime}(z)<0$, and this equilibrium point is the evolutionary stability strategy of the three sides system.

$$
\left\{\begin{array}{l}
\frac{\partial F(x)}{\partial x}=(1-2 x)\left[y(b+p)+z\left(m_{3}+e\right)+\left(\lambda_{1}-\lambda_{2}\right)\right] \\
\frac{\partial F(y)}{\partial y}=(1-2 y)\left[x\left(s_{g 1}-s_{g 2}-b-p-r\right)+x z\left(r-m_{2}\right)-z r+p+r-c_{g}\right] \\
\frac{\partial F(z)}{\partial z}=(1-2 z)\left[x y\left(m_{2}-r\right)+y r+s_{f}+m_{1}-c_{f}\right]
\end{array}\right.
$$

\subsection{The Solution of the Stable Strategy of the Tripartite Evolutionary Game}

The model continues to construct the Jacobi matrices of the tripartite evolutionary game, analyze the local stability, and discuss the equilibrium and stability points of the system. The Jacobi matrices of the tripartite evolutionary game are shown in Equations (16) and (17).

$$
\begin{gathered}
J=\left[\begin{array}{lll}
J_{11} & J_{12} & J_{13} \\
J_{21} & J_{22} & J_{23} \\
J_{31} & J_{32} & J_{33}
\end{array}\right]=\left[\begin{array}{lll}
\frac{\partial F(x)}{\partial x} & \frac{\partial F(x)}{\partial y} & \frac{\partial F(x)}{\partial z} \\
\frac{\partial F(y)}{\partial x} & \frac{\partial F(y)}{\partial y} & \frac{\partial F(y)}{\partial z} \\
\frac{\partial F(z)}{\partial x} & \frac{\partial F(z)}{\partial y} & \frac{\partial F(z)}{\partial z}
\end{array}\right] . \\
\left\{\begin{array}{l}
J_{11}=(1-2 x)\left[y(b+p)+z\left(m_{3}+e\right)+\left(\lambda_{1}-\lambda_{2}\right)\right] \\
J_{12}=x(1-x)(b+p) \\
J_{13}=x(1-x)\left(m_{3}+e\right) \\
J_{21}=y(1-y)\left[\left(s_{g 1}-s_{g 2}-b-p-r\right)+z\left(r-m_{2}\right)\right] \\
J_{22}=(1-2 y)\left[x\left(s_{g 1}-s_{g 2}-b-p-r\right)+x z\left(r-m_{2}\right)-z r+p+r-c_{g}\right] \\
J_{23}=y(1-y)\left[x\left(r-m_{2}\right)-r\right] \\
J_{31}=z(1-z)\left[y\left(m_{2}-r\right)\right] \\
J_{32}=z(1-z)\left[x\left(m_{2}-r\right)+r\right] \\
J_{33}=(1-2 z)\left[x y\left(m_{2}-r\right)+y r+s_{f}+m_{1}-c_{f}\right]
\end{array}\right.
\end{gathered}
$$

Based on the above analysis, the tripartite evolutionary game model has nine equilibrium points from $B_{1}$ to $B_{9}$. $B_{9}\left(x^{*}, y^{*}, z^{*}\right)$ exists under certain value conditions, but is not asymptotically stable. In addition, this article focuses on studying the evolution and development of the port's green logistics 
when the government adopts regulatory policy measures or when the third-party organization plays an evaluation role. Therefore, when analyzing the stability and equilibrium strategy of the three sides, the Lyapunov indirect method is used to analyze the stability of four equilibrium points $B_{5}(1,0,0)$, $B_{6}(1,0,1), B_{7}(1,1,0)$, and $B_{8}(1,1,1)$ in this paper.

(1) Analyze the point $B_{8}(1,1,1)$ when $-(b+p)-\left(m_{3}+e\right)-\left(\lambda_{1}-\lambda_{2}\right)<0,-s_{g 1}-s_{g 2}-b-m_{2}-c_{g}<$ $0, c f-s f-m_{1}-m_{2}<0$ is satisfied, then $B_{8}(1,1,1)$ is an evolutionary stable point; otherwise, the point is an unstable point or a saddle point. In this constraint let $\lambda_{1}-\lambda_{2}$ represent the difference in return before and after the port increased investment in green logistics construction, which may be positive or negative; let $b+p$ represent the sum of subsidies and fines when the government employs regulatory measures as part of the implementation of overall port control policies; let $m_{3}+e$ represent the sum of the social reputation and governance costs for the port when the third-party organization makes an evaluation and the quantitative evaluation impacts on the port; let $b+m_{2}+c_{g}$ represent the sum of government supervision costs, subsidies to the port, and rewards to third-party organizations when the government undertakes supervision measures; let $s_{f}+m_{1}+m_{2}$ represent the overall subsidies and government rewards obtained when the third-party organization conducts an evaluation and the port achieves government standards. Therefore, when the income difference before and after the increase in green logistics construction investment in the port is less than the sum of the government's overall control policy strength and the influence of the third-party evaluation, then the government's overall benefit from supervision is greater than the cost and control efforts paid, and the third-party organization evaluates the cost as being less than the overall subsidy and government rewards received, meaning the stable tripartite evolutionary strategy is increasing investment, supervising, and evaluating.

(2) Analyze the point $B_{7}(1,1,0)$ when $-(b+p)-\left(\lambda_{1}-\lambda_{2}\right)<0,-s_{g 1}-s_{g 2}-b-c_{g}<0, m_{1}+m_{2}+$ $s f-c f<0$ is satisfied, then $B_{7}(1,1,0)$ is an evolutionary stable point; otherwise, the point is an unstable point or a saddle point. In this constraint, when the evaluation cost for the third-party organization is greater than the overall subsidy it receives, then it will not perform evaluation work; when the government's control of the port is sufficient to make up for poor returns from the port's green logistics, then the port will increase investment in green logistics construction. The government's benefits are then greater than the cost of supervision and regulation, and it therefore will also choose a supervision strategy. At this time, the stable tripartite evolutionary strategy is increasing investment, supervising, and not evaluating.

(3) Analyze the point $B_{6}(1,0,1)$ when $-\left(m_{3}+e\right)-\left(\lambda_{1}-\lambda_{2}\right)<0, s_{g 1}-s_{g 2}-b-m_{2}-c_{g}<0, c f-$ $m_{1}-s f<0$ is satisfied, then $B_{6}(1,0,1)$ is an evolutionary stable point; otherwise, the point is an unstable point or a saddle point. In this constraint, when the government's revenue is less than the cost of supervision, then it will not supervise the port's green logistics. Therefore, the port, only when the third-party organization's quantitative evaluation results have a sufficient impact on it, will then choose to increase green investment. At this time, the stable tripartite evolutionary strategy is increasing investment, not supervising $\mathrm{p}$, and evaluating.

(4) Analyze the point $B_{5}(1,0,0)$ when $-\left(\lambda_{1}-\lambda_{2}\right)<0, s_{g 1}-s_{g 2}-b-c g<0, s f-c f+m 1<0$ is satisfied, then $B_{5}(1,0,0)$ is an evolutionary stable point; otherwise, the point is an unstable point or a saddle point. At this time, the port can already benefit from the strategy of increasing investment in green logistics construction and is in the ideal stage of evolution. The government and third-party organizations will not conduct supervision and evaluation. The stable tripartite evolutionary strategy is increasing investment, not supervising, and not evaluating.

By analyzing the parameter conditions of the above four evolutionary stability strategies, the following points can be summarized:

(1) Before the port has benefited from increasing investment in green intelligent port construction, $\lambda_{1}-\lambda_{2}$ is a negative number, and the government and third-party organizations always need to play a regulatory and evaluation role. The government's macro-control policy intensity $b+p$ and the quantitative impact of third-party evaluation on the port $m_{3}+e$ will produce different port evolution 
strategies. In the next section of numerical simulation analysis, this article will discuss the impact of these specific two values on the equilibrium speed of port evolution.

(2) Whether the government conducts supervision depends on the cost of government supervision $c_{g}$, the subsidy $b$ for the port, and the reward $m_{2}$ for the evaluation work of the third-party organization. When the port increases investment in green logistics construction and the government's revenue is greater than the government's macro-control efforts, then the government will strengthen supervision.

(3) Whether the third-party organization performs an evaluation depends on the evaluation $\operatorname{cost} c_{f}$, government subsidies $m_{1}$, government rewards $m_{2}$, and social subsidies $s_{\mathrm{f}}$. Whether the port benefits from green logistics will not affect its evaluation work.

\subsection{Stable Strategy Solution for the Diffusion Model}

In order to study the specific influence of regulation and control means on the government and the third-party organization during the construction and diffusion of a green intelligent port, the stability strategy solution and analysis of the construction and diffusion model of green intelligent ports can be further carried out.

Let $\frac{d h_{1}(t)}{d t}=\frac{d h_{2}(t)}{d t}=0$ in Equation (18) be used to find the equilibrium solution in the model:

$$
\left\{\begin{array}{l}
\frac{d h_{1}(t)}{d t}=a_{1} h_{1}\left(1-\frac{h_{1}}{N_{1}}-\gamma_{12} \frac{h_{2}}{N_{1}}\right)=0 \\
\frac{d h_{2}(t)}{d t}=a_{2} h_{2}\left(1-\frac{h_{2}}{N_{2}}-\gamma_{21} \frac{h_{1}}{N_{2}}\right)=0
\end{array}\right.
$$

The four equilibrium solutions in the equations are $L 1(0,0), L 2\left(N_{1}, 0\right), L 3\left(0, N_{2}\right)$, and $L 4\left(\frac{N_{1}-\gamma_{12} N_{2}}{1-\gamma_{12} \gamma_{12}}\right.$, $\left.\frac{N_{2}-\gamma_{21} N_{1}}{1-\gamma_{12} \gamma_{12}}\right)$. According to the summary, there are four stages of evolutionary paths between the government and the port. Before the port benefits from the strategy of increasing the construction of green intelligent ports, the government always needs to strengthen the means of regulation and control, reduce the cost of evaluation, and intervene in the construction of green intelligent ports, so as to obtain an evolutionary stability solution. This also fully demonstrates the importance of the third-party organization evaluation.

1. Initial stage: in the evolution system, the government chooses not to evaluate the port due to a lack of motivation for evaluation and supervision, and the port chooses not to strengthen the construction of green intelligent ports due to a lack of corresponding supervision and the high construction costs for green intelligent ports. At this time, $N_{1}>N_{2} / \gamma_{21}, N_{2}>N_{1} / \gamma_{12}, \gamma_{12}>\gamma_{21}$. The inhibition coefficient of the general port to the green intelligent port is greater than the substitution coefficient of the green intelligent port. The general port occupies a larger market and has a wider diffusion range, forming the pattern shown in Figure 1. The shaded area indicates the market occupied by general ports.

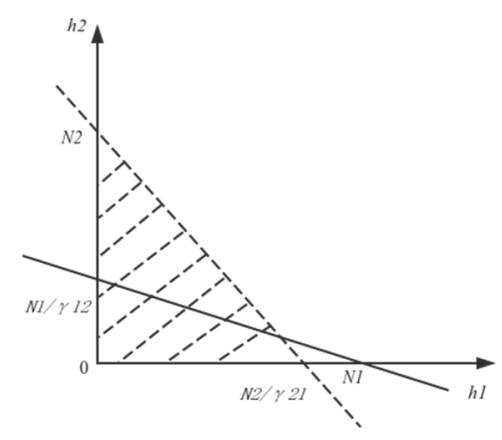

Figure 1. Initial diffusion mode.

2. Evolution stages: A certain number of ports have begun to increase the construction of green intelligent ports. The two types of port diffusion models have gradually developed and changed. 
At this time, competitive and complementary diffusion can be formed between ports. As shown in Figure 2a, because of government regulation and control, the market share of green intelligent ports gradually increases, forming a competitive relationship with standard ports. There is a certain market competition relationship between the trunk hub ports of adjacent port groups and the feeder ports in the port group. If some ports choose to increase the construction of green intelligent ports and get government subsidies accordingly, then these ports gradually start to transform and gain more market share. As shown in Figure $2 b$, now $N_{1}<N_{2} / \gamma_{21}, N_{2}<N_{1} / \gamma_{12}, \gamma_{12}<\gamma_{21}$. The substitution coefficient of green intelligent ports increases, and these ports can form complementary diffusions with the government's support.

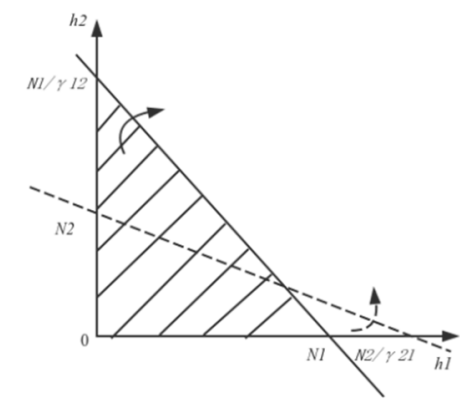

(a) No regulation

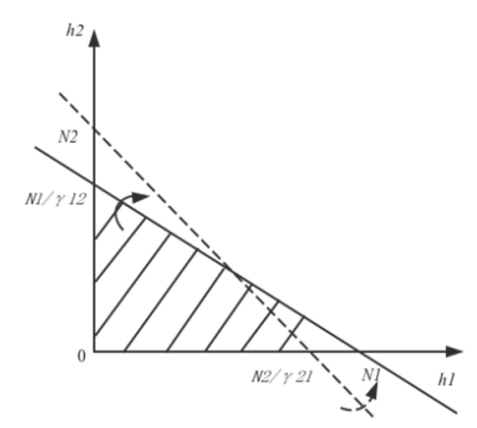

(b) Start regulating

Figure 2. Diffusion patterns in the evolution stage.

3. The ideal stage: evolution enters the final ideal stage, and the stable solution is $(1,0)$, that is, the port increases the construction of the green intelligent port and continues to carry out technological innovation, strengthen energy conservation, increase emission reduction efficiency, reduce the cost of green intelligent port construction, and improve its green income. In addition, through government guidance, the sustainable development and the concept of social responsibility of the port market are strengthened. The green port market has gradually increased, and eventually the ports will continue to increase investment in green intelligent port construction, and the government will leave evaluation to the port. As shown in Figure $3, N_{1}>N_{2} / \gamma_{21}, N_{2}>N_{1} / \gamma_{12}$ and $\gamma_{12}<\gamma_{21}$.

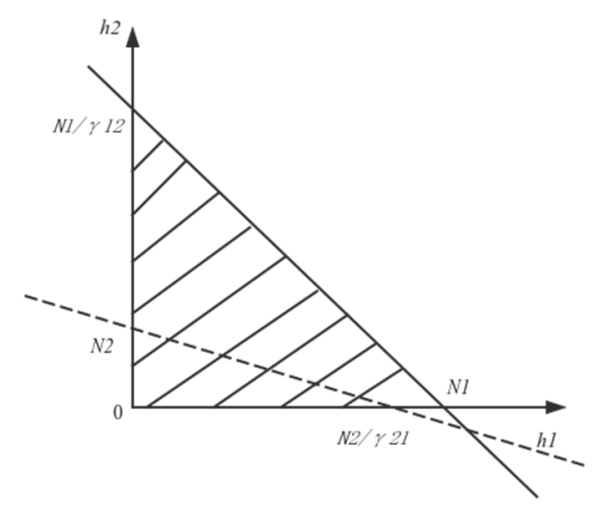

Figure 3. Diffusion pattern at the ideal stage.

\section{Simulation Analysis}

Based on the replication dynamic equation and parameter constraints in the tripartite evolutionary game model, we used MATLAB for further numerical simulation so that we could intuitively analyze the evolutionary stability results through the simulation diagram. From the above studies, we can see that the important condition involving $\lambda_{1}-\lambda_{2}$ for reaching the ideal stage of evolution $(1,0,0)$ is 
whether it is positive, which determines whether the port can benefit from progressing with green intelligent investment. Before the port can benefit from investment in a green intelligent port, it always needs the government and third-party organizations to play a role in regulation, so as to encourage the port to accelerate its green transformation. Therefore, in the numerical simulation, we mainly analyzed the three stable points $B_{7}(1,1,0), B_{6}(1,0,1)$, and $B_{8}(1,1,1)$.

\subsection{The Impact of Random Initial Strategy on Evolutionary Stability}

First, we analyzed the impact of the three sides random initial strategy on the evolutionary stability. This paper took $x, y$, and $z$ as the coordinate axes. Let the evolution start time be 0 and the evolution end time be 10 . We randomly selected 50 initial strategy points for $x, y$, and $z$, observed whether the evolution trend at termination was consistent with the model solution, and observed the influence of the initial strategy probabilities of $x, y, z$ on the rate of evolutionary stability.

(1) The impact of random initial strategy on evolutionary stability under the state of $B_{7}(1,1,0)$.

According to the constraint conditions of evolutionary stability parameters at this point, the parameter values were set to $\lambda_{1}=1300, \lambda_{2}=2800, e=550, m_{3}=50, c_{g}=120, m_{1}=600, b=750$, $p=750, z_{g}=5000, s_{g 1}=2500, s_{g 2}=1000, c_{f}=900, s_{f}=200, m_{2}=60$, and $r=40$. As shown in Figure 4, we found that the 50 random initial points eventually converged to the point $(1,1,0)$, but the directions in the convergence process were different. When the initial point probability of $x, y, z$ is small, $x$ will first tend to 0 , then slowly extend to the stable point of evolution. This trend decreases as the probability of $y$ or $z$ increases. This shows that the initial point probability of the government and the third-party organization has an impact on $x$. If the initial point probability of $x$ is low, then the government and the third-party organization need to strengthen the regulations and control so that they promote the evolutionary stability of the tripartite game model.

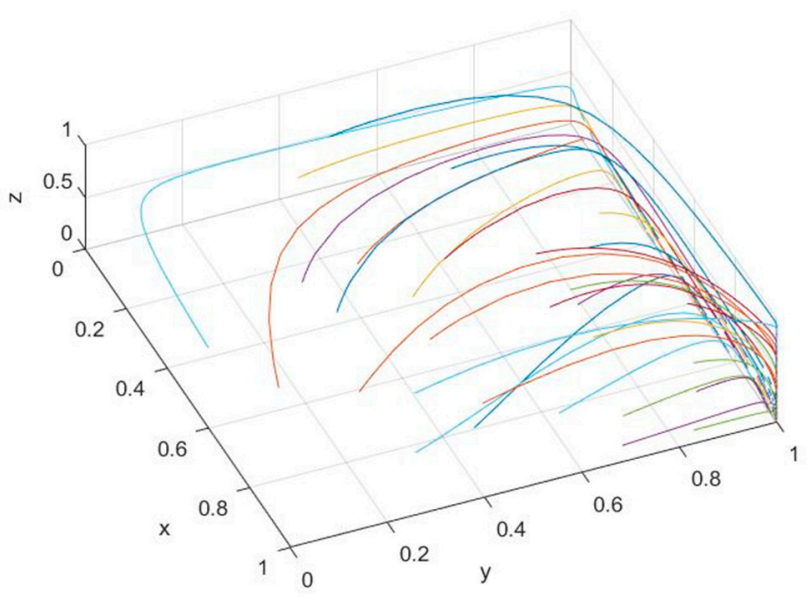

Figure 4. Random dot figure of the evolutionary trend of $B_{7}(1,1,0)$.

(2) The impact of the random initial strategy on evolutionary stability under the state of $B_{6}(1,0,1)$. According to the constraint conditions of evolutionary stability parameters at this point, the parameter values were set to $\lambda_{1}=2200, \lambda_{2}=2800, e=450, m_{3}=150, c_{g}=120, m_{1}=600$, $b=750, p=762, z_{g}=5000, s_{g 1}=1800, s_{g 2}=1000, c_{f}=700, s_{f}=200, m_{2}=60$, and $r=40$. As shown in Figure 5, all random initial probability points eventually converged to $(1,0,1)$. When the initial probability is low, as shown in the curve, the probability of $y$ will first tend to 1 , then trend toward evolutionary stability. The trend decreases as the initial probability of $x$ or $z$ increases.

(3) The impact of random initial strategy on evolutionary stability under the state of $B_{8}(1,1,1)$.

According to the constraints of the evolutionary stability parameters at this point, the parameter values are set to $\lambda_{1}=1300, \lambda_{2}=2800, e=350, m_{3}=250, c_{g}=120, m_{1}=600, b=450, p=520, z_{g}=5000$, $s_{g 1}=2500, s_{g 2}=1000, c_{f}=700, s_{f}=200, m_{2}=60$, and $r=40$. As shown in Figure 6 all random initial probability points eventually converge to $(1,1,1)$, but the curve also has an "inflection point". From the 
figure, we can find that part of the curve initially extends in the direction where $x$ is 0 . Some curves have larger inflection points. As the initial probability of $z$ continues to increase, the $x$ inflection point becomes smaller and eventually tends to a stable point. At this point, the evaluation probability of the third-party organization has a greater impact on the port.

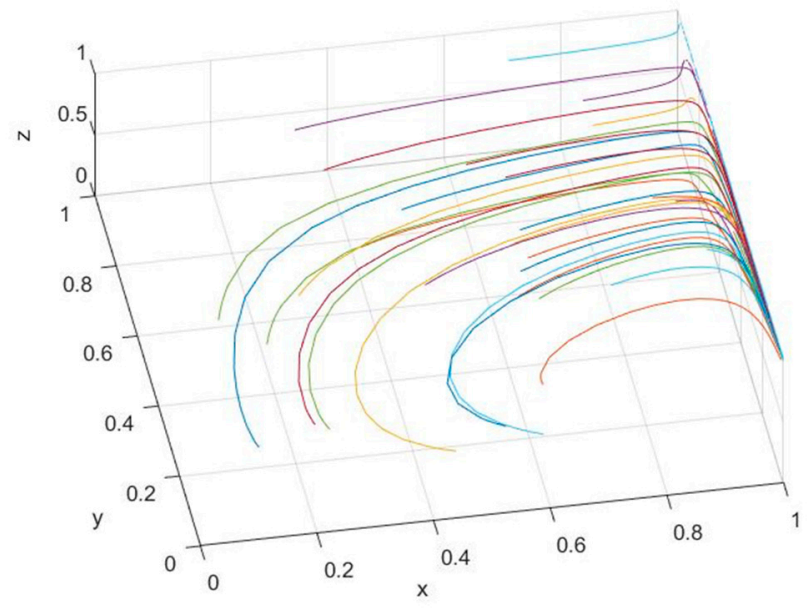

Figure 5. Random dot figure of the evolutionary trend of $B_{6}(1,0,1)$.

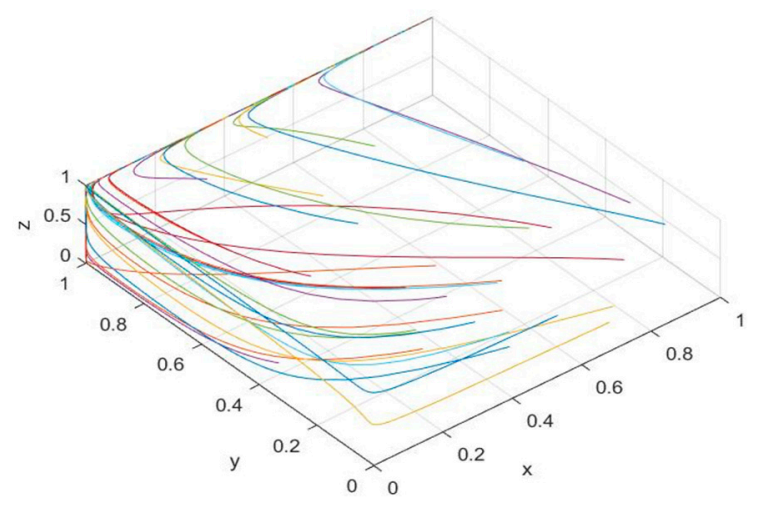

Figure 6. Random dot figure on the evolutionary trend of $B_{8}(1,1,1)$.

\subsection{The Impact of Government and the Third-Party Organization Regulation on the Speed of}

\section{Evolutionary Equilibrium}

As discussed above, under different stable points, the main factors affecting the choice of port strategy are not only whether or not the port itself benefits; the government's macro-control policies and the quantitative impact of third-party evaluations will also play important roles. In this section, we carry out a numerical simulation of the speed of evolutionary equilibrium involving the regulation and control by government and third-party organizations at various stable points.

(1) The impact of government regulation on the speed of evolutionary equilibrium.

The parameter constraints indicate that the selection of port strategy under the stable point $B_{7}(1,1,0)$ is mainly affected by $b+p$. Therefore, let $b+p$ take three sets of values of low, medium, and high levels, respectively, and their values represent the impact of the government's macro policy on the rate of system evolutionary equilibrium. In Figure 7, the values of $b$ and $p$ are $(750,750)$, $(1000,1000)$, and $(1200,1200)$, and the initial probabilities of the three sides take the same value as 0.5. After multiple games, they finally converge to the $(1,1,0)$ state. When the value of $b+p$ is $(1200$, $1200)$, the rate of tending to the evolutionary stable point is the fastest; when the value is $(750,750)$, the rate of tending to the evolutionary stable point is the slowest. This shows that in this stable state, the government's regulatory policies have a positive effect on the evolutionary stability state of the 
three sides. In particular, the greater the overall control of the port, the faster the port chooses to increase green construction investment.

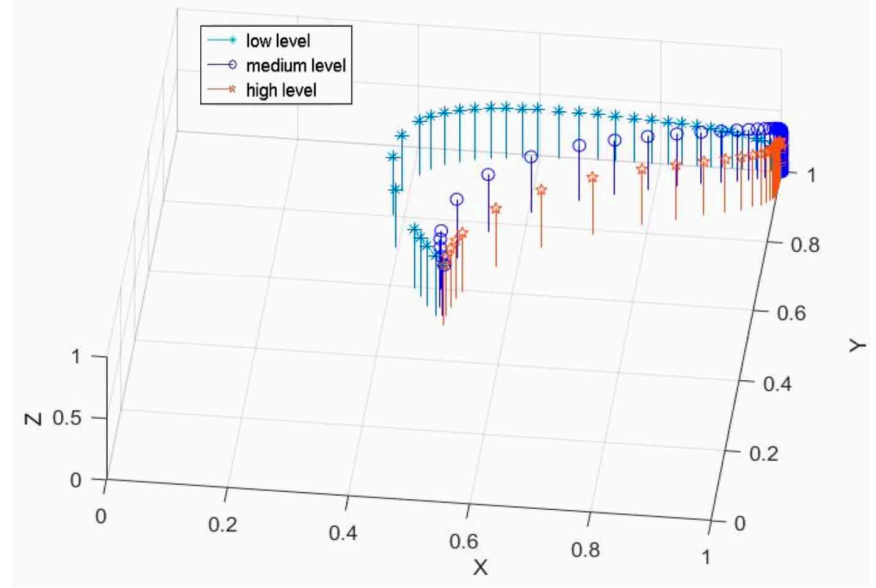

Figure 7. The impact of government regulation on the speed of evolutionary equilibrium.

(2) The impact of the third-party organization regulation on the speed of evolutionary equilibrium.

The parameter constraints indicate that the port strategy selection under the stable point $B_{6}(1,0$, 1 ) is mainly affected by $m_{3}+e$. Therefore, let $m_{3}+e$ take three sets of values of low, medium, and high levels, respectively, and their values represent the quantitative impact of the evaluation results of third-party organizations on the port, and then how they affect the rate of system evolutionary stability can be analyzed. As shown in Figure 8, $m_{3}$ and $e$ respectively take the values $(150,450),(350,750)$, $(750,1050)$, and the initial probabilities of the three sides take the same value as 0.5 . After multiple games, they finally converge to $(1,0,1)$ state. When the value of $m_{3}+e$ is low, the evolution rate reaches its slowest level, and when the value is high, the evolution rate reaches its fastest level. However, it can be seen from the figure that under different value levels, there is little difference in the rate of evolutionary equilibrium. This indicates that in the steady state, the third-party organization plays a positive role in the evolutionary stability of the three sides. However, compared with the above figure, it can be found that its effect on evolutionary stability is not as great as that of the government's macro-control efforts. The impact of the evaluation results on the port is not considerable enough. This also confirms the current status of Chinese evaluation of green intelligent ports; the influence of the government is large, while the influence of third-party organizations needs to be strengthened.

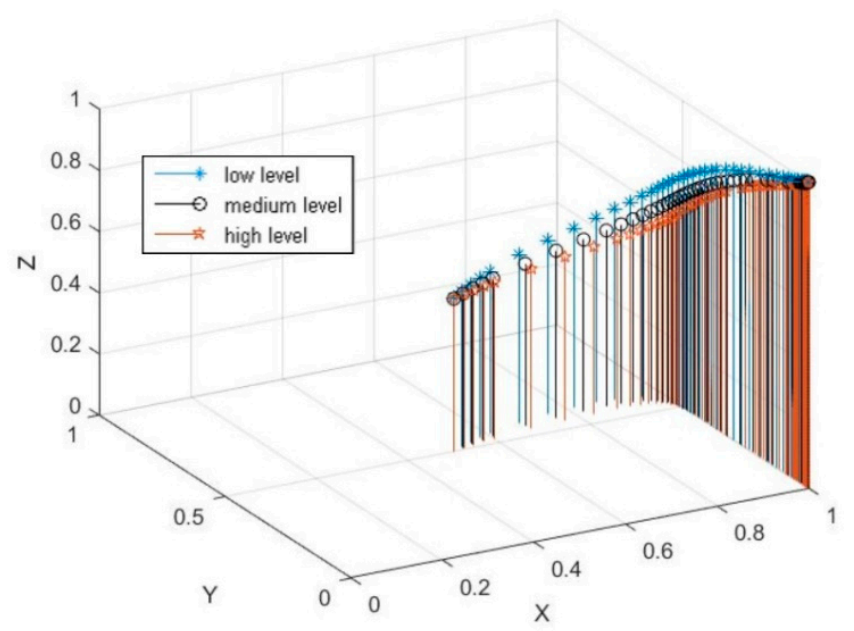

Figure 8. The impact of regulation by third-party organizations on the speed of the evolutionary equilibrium. 
(3) The impact of government regulation and the whole effect of the third-party organization on the speed of the evolutionary equilibrium.

The parameter constraints indicate that the port strategy selection under the stable point $B_{8}(1,1$, 1 ) is mainly affected by $b+p$ and $m_{3}+e$. Therefore, the values of the two sets can be adjusted at the same time. The values of $b+p$ and $m_{3}+e$ are taken at low, medium, and high levels, respectively, to analyze the steady rate of system evolution under the collective effect of both sides. As shown in Figure $9, b+p, m_{3}+e$ take the values $(970,600),(1200,800)$, and $(1450,980)$, respectively. The initial probabilities of the three sides take the same value of 0.5 , and they finally converge to a $(1,1,1)$ state. The three curves tend to be balanced and are obviously different. The low-level curve tends to stabilize at the slowest rate, and the high level tends to stabilize at the fastest rate. This indicates that when the government and third-party organizations play a positive role in the equilibrium of the three sides evolution, high-level control and evaluation will encourage the port to increase green intelligent port investment construction.

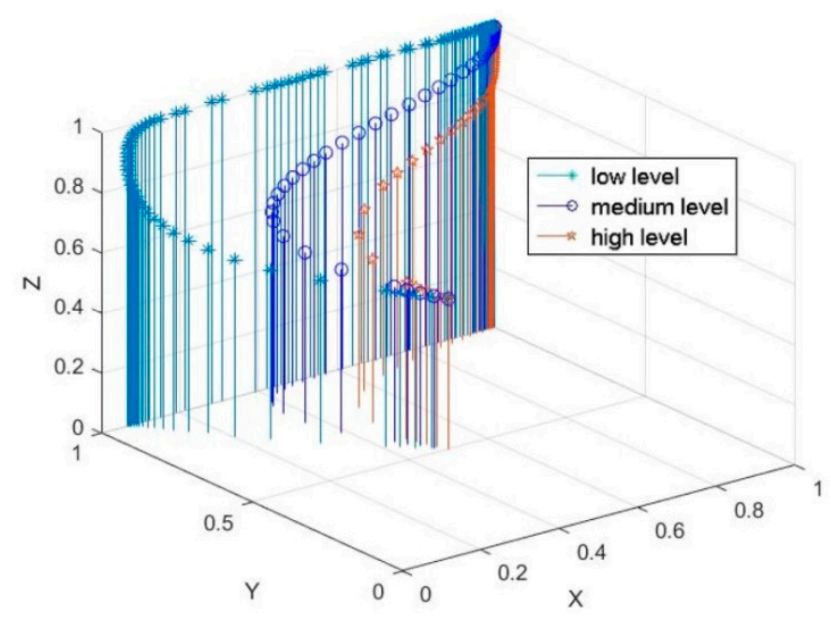

Figure 9. The impact of government regulation and the overall effect of third-party organizations on the speed of the evolutionary equilibrium.

\subsection{The Sensitivity Analysis of the Diffusion Model}

We continued to simulate the Lotka-Volterra diffusion model constructed above. The initial value was first set as $N_{1}=N_{2}=1000$, and the evolution time was $(0,100)$.

In the initial stage, we set $\gamma_{12}=0.7$ and $\gamma_{21}=0.5$, which means that the basic port suppression coefficient is greater than the coefficient for the port that increases the construction of a green intelligent port. $\alpha_{1}=\alpha_{2}=0.3$, which means that the government subsidy coefficient is the same as the penalty coefficient. The operation result is shown in Figure 10. In this state, most of the ports are in the primary transformation stage, and the government has not strengthened its regulations and control. The two types of ports are in a normal spreading state and gradually flatten as the number of simulations increases.

As the government gradually increases subsidies and penalties, the inflection point of diffusion begins to appear on the market. As shown in Figure 11a,b, the two figures are set as $\alpha_{1}=0.3, \alpha_{2}=0.5$, and $\alpha_{1}=0.5, \alpha_{2}=0.8$. We can see that with the strengthening of government regulation and the increase in the number of evolutions, the number of ports that increase the construction of green intelligent ports gradually increases, and it begins to surpass the number of standard ports over time. Zhang found that increasing punishments is one of the ways for a government to maintain a good evaluation level, and it is also one of the methods that can be used to ensure the positive transformation of the game $[8,16,30,48]$. In the early stages of evolution, if the transformation cost of enterprises is high, then the government must increase subsidies or increase penalties to ensure the survival of enterprises in transition [41,49]. 


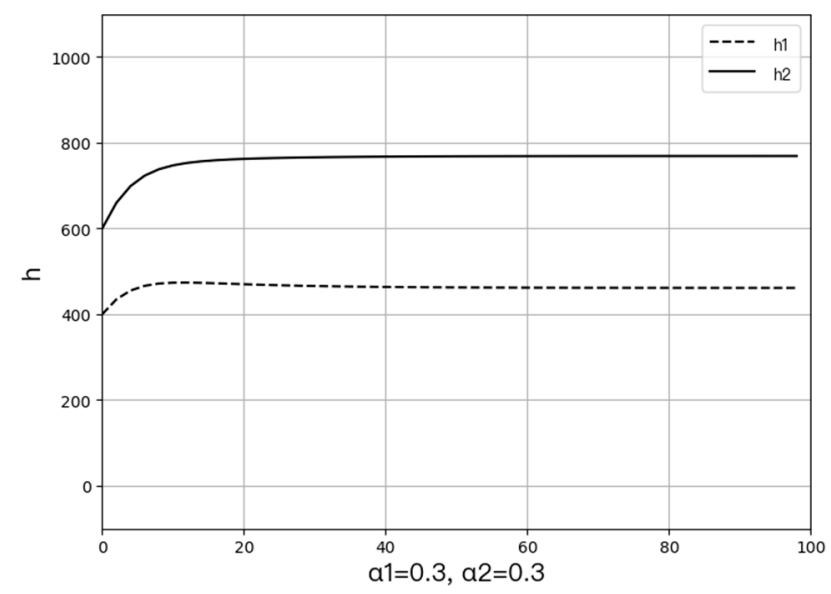

Figure 10. Simulation of the initial state diffusion.

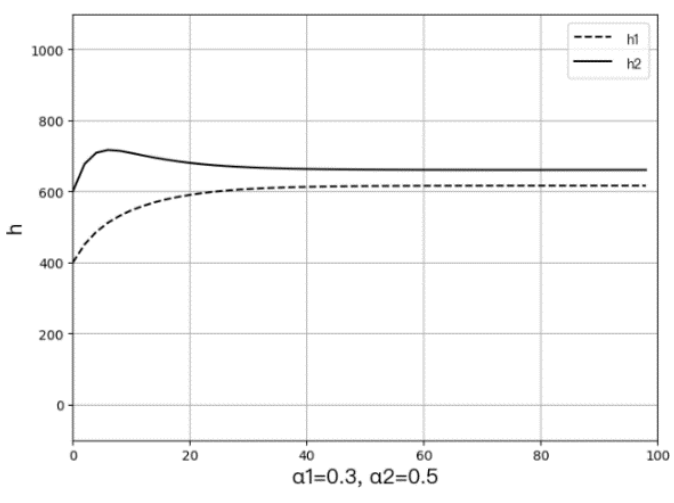

(a). Low level regulation

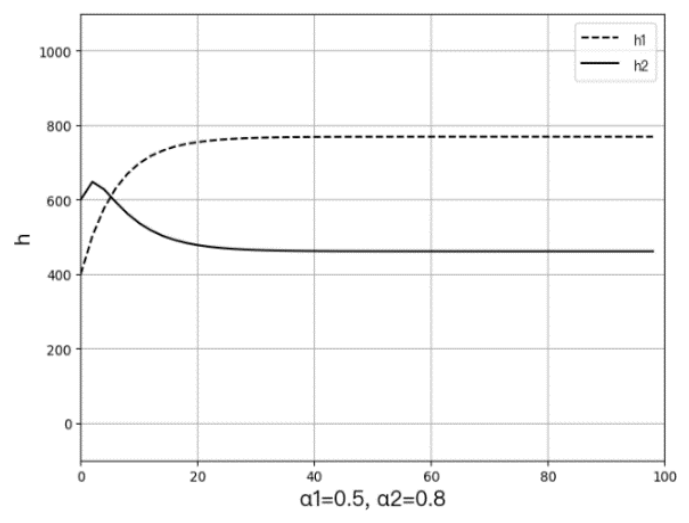

(b). High level regulation

Figure 11. Diffusion simulation of the first stage of evolution.

As the evolution path progresses further, set $\alpha_{1}=0.8$ and $\alpha_{2}=0.4$, as seen in Figure 12 . It can be seen from the simulation diagram that the government further increased the subsidy coefficient and lowered the penalty coefficient in the later stage of evolution, which helped to further expand the market for green intelligent ports, and the replacement factor of green intelligent ports was also gradually increasing.

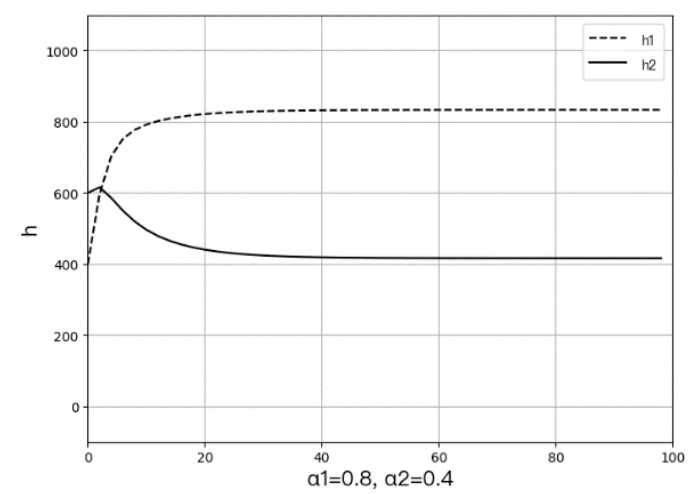

Figure 12. Diffusion simulation of the second stage of evolution. 


\section{Conclusions and Management Implications}

\subsection{Conclusions}

Based on the assumption of bounded rationality of the government, port, and third-party organization, game theory was introduced to construct the evolution game matrix of the three sides, and the evolution game of development and construction of the green intelligent port under the government regulation and control was discussed. The impact of factors such as the construction costs and governance costs of port transformation, the performance of green intelligent ports, and the economic and social benefits of the construction of green intelligent ports were considered, and then the main influencing factors such as government evaluation and supervision costs, policy subsidies, green performance benefits, and higher-level government incentives were discussed. Combined with the cost of third-party organization evaluation and the funding obtained, an evolutionary game matrix "government-port-third-party organization" was established. The expected return function of the three sides according to the game matrix was calculated to obtain the average expected return of the government, the port, and the third-party organization. Then, a replication dynamic equation was built to solve the unilateral stable strategy. Combined with the replicator dynamic equations of three sides, the Jacobian matrix of the game matrix system was constructed, and its local stability analysis was performed to obtain the equilibrium stability point of the entire system. Model simulations were used to verify the accuracy of the equilibrium stability points, and diffusion simulations were used to observe the specific impact of government regulation and control on port transformation. The main contribution of this paper includes: This paper analyzes the impact factors of ports, the government, and third-party organizations, especially the cost and benefit factors for the three sides of the development of green intelligent ports. By constructing a joint decision game matrix that reflects the decision-making return coefficients of the three sides and determines the stable strategy points of the three sides, the shortcomings in the existing research that do not conclude the development path of green intelligent port construction are overcome, and the restrictive relationship between the port, the government, and the third-party organization is described.

The results show that:

1. Under the mode of third-party organization evaluation and government supervision, an evolutionary game model based on the assumption of bounded rationality of the government, port, and third-party organization was constructed, and eight equilibrium points of the system were determined by solving the differential equation. Based on the requirements of this paper, the four equilibrium points were screened and stability analysis was carried out. It was found that the main factors affecting the choice of port strategy are its own benefits of becoming a green intelligent port $\left(\lambda_{1}-\lambda_{2}\right)$, the intensity of government regulation $(b+p)$, and the quantitative influence of the third-party evaluation results on the port strategy selection $\left(m_{3}+e\right)$. The main factors influencing the government's choice of strategy include the cost of its own regulation $\left(c_{g}\right)$, subsidies for ports $(b)$, and incentives for evaluation of third-party organizations $\left(m_{2}\right)$. Whether the third-party organization conducts an evaluation depends largely on the evaluation cost $\left(c_{f}\right)$ and the funding received $\left(s_{f}+m_{1}+m_{2}\right)$, independent of the benefit of the port $\left(\lambda_{1}-\lambda_{2}\right)$.

2. In the absence of government regulation or the influence of third-party organizations, ports will not actively increase the green intelligent port construction investment in the initial strategy selection. The government always needs to play a macro-control role before it can benefit. If both the government and the third-party organization adopt the high probability initial strategy, the evolution and stability rate of the port will be accelerated, and the construction of green intelligent ports will be promoted faster. Moreover, compared with the macro-control policies of the government, the influence of the third-party organization on the port is significantly smaller. 


\subsection{Management Implications}

Through the discussion of the results, this paper summarizes some policy implications that may be helpful to policy makers. These policy makers should:

1. Establish a set of evaluation index systems and evaluation models of port transformation intention, and conduct scientific and reasonable evaluations of port greenness and intelligence. By establishing a streamlined and informative evaluation index system, the government can not only improve the evaluation efficiency and reduce the evaluation cost of the current status of a port, but also can rank the development of the port based on the evaluation results. By analyzing the scores of different criterion layers and indicator layers, the port can be urged to carry out key rectifications of certain aspects and strengthen them in a targeted manner, thereby improving the transformation efficiency.

2. Motivate the enthusiasm of third-party supervision and public supervision to improve the concept of socially sustainable development. The construction of green intelligent ports not only requires the evaluation and supervision of the government, but can also be entrusted to third-party intermediary organizations such as NGOs to evaluate and supervise the ports. The government only plays an appropriate regulatory role, which can save costs and provide policy support for the ports. In addition, the government's publicity of green intelligent ports through official channels can improve the public's acceptance of green intelligent ports, thus encouraging a side supervision role for ports by consumers and strengthening the construction of a corporate social responsibility for ports.

3. Encourage innovative technology research and development of green intelligent ports, improve resource utilization, reduce port costs, and weaken port resistance to transformation. As an integrated hub, port logistics consume a large amount of energy through storage, transportation, loading, unloading, handling, etc. The use of high-tech and scientific means to save energy and promote energy recycling is not only a good way to reduce the cost of port production, but also an important consideration in the port transformation process. On the other hand, in order to ensure the smooth transformation of the port, the government can also reduce taxes related to the port and improve the port's revenue.

4. With the support of relevant government subsidies, ports should intensify their investment and construction efforts, construct reasonable action plans for key construction projects for green intelligent ports, such as automation transformation, sewage treatment facility transformation, and energy-saving standard system construction, and continuously evaluate and strategically adjust according to operating conditions, which helps ports to reduce energy consumption and reduce emissions of carbon dioxide and other waste gases and wastewater while improving operating efficiency. Through the transformation and upgrading of the loading and unloading of equipment, vehicles, and vessels operating in ports, governance costs can also be reduced, optimization of port energy structure can be strengthened, and further moves can be made toward developing a green intelligent port.

\subsection{Limitations}

Due to limited research availability and time, as well as other subjective and objective factors, there are some shortcomings in this article that can be improved in future research: (1) The evolutionary game subject and parameter settings can be further optimized. The subject and parameter assumptions studied in this article list only the main influencing factors, and there are many other factors to be discovered that affect the construction of green intelligent ports. For example, the model and parameters can be further improved from the perspective of node companies or consumers in the port supply chain. (2) The evolutionary game model needs to be further improved. We built relevant models based on evolutionary game theory. In future research, we can also combine prospect theory and other more complex models to make them more realistic. (3) Parameter assignment in numerical 
simulation is only an approximate estimation of the current port development data. In the future, we can conduct specific investigations and further study the model parameter values after collecting actual sample data.

Author Contributions: Funding acquisition, H.K.; Methodology, B.M., H.K., E.N. and J.L. Resources, J.L. and Z.L.; Software, B.M. and E.N. All authors have read and agreed to the published version of the manuscript.

Funding: The research was funded by The National Natural Science Foundation of China [71831002; 71731003; 71873103; 71971034]; Changjiang Scholars and Innovation Team Development Program [IRT_17R13]; Fundamental Research Funds for the Central Universities [3132019325,3132019326]. We thank the organizations mentioned above.

Conflicts of Interest: The authors declare that there is no conflict of interests regarding the publication of the paper.

\section{References}

1. Aregall, M.G.; Bergqvist, R.; Monios, J. A global review of the hinterland dimension of green port strategies. Transp. Res. Part D-Transp. Environ. 2018, 59, 23-34. [CrossRef]

2. Lee, T.; Yeo, G.T.; Thai, V.V. Environmental efficiency analysis of port cities: Slacks-based measure data envelopment analysis approach. Transp. Policy 2014, 33, 82-88. [CrossRef]

3. Yang, L.; Cai, Y.; Wei, Y.; Huang, S. Choice of technology for emission control in port areas: A supply chain perspective. J. Clean. Prod. 2019, 240, 82-88. [CrossRef]

4. Barnes-Dabban, H.; van Tatenhove, J.P.; van Koppen, K.C.; Termeer, K.J. Institutionalizing environmental reform with sense-making: West and Central Africa ports and the 'green port' phenomenon. Mar. Policy 2017, 86, 111-120. [CrossRef]

5. State Council of China. Notice of the State Council on Printing and Distributing the Development Plan of Modern Comprehensive Transportation System During the 13th Five Year Plan; GF: Beijing, China, 2017; No. 11.

6. Ministry of Transportation of China. The Letter of the General Office of the Ministry of Transport on Soliciting Opinions on the Action Plan for Further Promoting the Construction of Green Port (2018-2022); Gbsh: Beijing, China, 2018; No. 480.

7. Bergqvist, R.; Egelszandén, N. Green port dues-The case of hinterland transport. Res. Transp. Bus. Manag. 2012, 5, 85-91. [CrossRef]

8. Teerawattana, R.; Yang, Y.C. Environmental performance indicators for green port policy evaluation: Case study of laem chabang port. Asian J. Shipp. Logist. 2019, 35, 63-69. [CrossRef]

9. Yang, Y.C.; Chang, W.M. Impacts of electric rubber-tired gantries on green port performance. Res. Transp. Bus. Manag. 2013, 8, 67-76. [CrossRef]

10. Chiu, R.H.; Lin, L.H.; Ting, S.C. Evaluation of green port factors and performance: A fuzzy AHP analysis. Math. Probl. Eng. 2014, 12, 1-12. [CrossRef]

11. Radwan, M.E.; Chen, J.; Wan, Z.; Zheng, T.; Hua, C.; Huang, X. Critical barriers to the introduction of shore power supply for green port development: Case of Djibouti container terminals. Clean Technol. Environ. Policy 2019, 21, 1293-1306. [CrossRef]

12. Luna, G.M.; Manini, E.; Turk, V.; Tinta, T.; D’Errico, G.; Baldrighi, E.; Baljak, V.; Buda, D.; Cabrini, M.; Campanelli, A.; et al. Status of faecal pollution in ports: A basin-wide investigation in the Adriatic Sea. Mar. Pollut. Bull. 2019, 147, 219-228. [CrossRef]

13. Mcarthur, D.P.; Osland, L. Ships in a city harbour: An economic valuation of atmospheric emissions. Transp. Res. Part D Transp. Environ. 2013, 21, 7-52. [CrossRef]

14. Chen, J.; Zheng, T.; Garg, A.; Xu, L.; Li, S.; Fei, Y. Alternative Maritime Power application as a green port strategy: Barriers in China. J. Clean. Prod. 2019, 213, 825-837. [CrossRef]

15. Wan, C.; Zhang, D.; Yan, X.; Yang, Z. A novel model for the quantitative evaluation of green port development-A case study of major ports in China. Transp. Res. Part D Transp. Environ. 2018, 61, 431-443. [CrossRef]

16. Ballini, F.; Bozzo, R. Air pollution from ships in ports: The socio-economic benefit of cold-ironing technology. Res. Transp. Bus. Manag. 2015, 17, 92-98. [CrossRef]

17. Homsombat, W.; Yip, T.L.; Yang, H.; Fu, X. Regional cooperation and management of port pollution. Marit. Policy Manag. 2013, 40, 451-466. [CrossRef] 
18. Daamen, T.A.; Vries, I. Governing the European port-city interface: Institutional impacts on spatial projects between city and port. J. Transp. Geogr. 2013, 27, 4-13. [CrossRef]

19. Poulsen, R.T.; Ponte, S.; Sornn-Friese, H. Environmental upgrading in global value chains: The potential and limitations of ports in the greening of maritime transport. Geoforum 2018, 89, 83-95. [CrossRef]

20. Carpenter, A.; Lozano, R.; Sammalisto, K.; Astner, L. Securing a port's future through Circular Economy: Experiences from the Port of Gävle in contributing to sustainability. Mar. Pollut. Bull. 2018, 128, 539-547. [CrossRef]

21. Puig, M.; Wooldridge, C.; Michail, A.; Darbra, R.M. Current status and trends of the environmental performance in European ports. Environ. Sci. Policy 2015, 48, 57-66. [CrossRef]

22. Lam, J.S.; Li, K.X. Green port marketing for sustainable growth and development. Transp. Policy 2019, 84, 73-81. [CrossRef]

23. Seguí, X.; Puig, M.; Quintieri, E.; Wooldridge, C.; Darbra, R.M. New environmental performance baseline for inland ports: A benchmark for the European inland port sector. Environ. Sci. Policy 2016, 58, $29-40$. [CrossRef]

24. Chen, J.; Huang, T.; Xie, X.; Lee, P.T.W.; Hua, C. Constructing Governance Framework of a Green and Smart Port. J. Mar. Sci. Eng. 2019, 7, 83. [CrossRef]

25. Acciaro, M.; Vanelslander, T.; Sys, C.; Ferrari, C.; Roumboutsos, A.; Giuliano, G.; Kapros, S. Environmental sustainability in seaports: A framework for successful innovation. Marit. Policy Manag. 2014, 41, 480-500. [CrossRef]

26. Vejvar, M.; Lai, K.; Lo, C.K.Y.; Fürst, E.W. Strategic responses to institutional forces pressuring sustainability practice adoption: Case-based evidence from inland port operations. Transp. Res. Part D Transp. Environ. 2018, 61, 274-288. [CrossRef]

27. Woo, J.K.; Moon, D.S.; Lam, J.S. The impact of environmental policy on ports and the associated economic opportunities. Transp. Res. Part A Policy Pract. 2018, 110, 234-242. [CrossRef]

28. Lam, J.S.; Notteboom, T. The greening of ports: A comparison of port management tools used by leading ports in Asia and Europe. Transp. Rev. 2014, 34, 169-189. [CrossRef]

29. Schipper, C.A.; Vreugdenhil, H.; DeJong, M.P. A sustainability assessment of ports and port-city plans: Comparing ambitions with achievements. Transp. Res. Part D Transp. Environ. 2017, 57, 84-111. [CrossRef]

30. Yang, Y.C.; Chen, S.L. Determinants of global logistics hub ports: Comparison of the port development policies of Taiwan, Korea, and Japan. Transp. Policy 2016, 45, 179-189. [CrossRef]

31. Mjelde, A.; Endresen, Ø.; Bjørshol, E.; Gierløff, C.W.; Husby, E.; Solheim, J.; Mjøs, N.; Eide, M.S. Differentiating on port fees to accelerate the green maritime transition. Mar. Pollut. Bull. 2019, 149, 110561. [CrossRef]

32. Tseng, P.; Pilcher, N. Evaluating the key factors of green port policies in Taiwan through quantitative and qualitative approaches. Transp. Policy 2019, 82, 127-137. [CrossRef]

33. Saeed, N.; Larsen, O.I. Container terminal concessions: A game theory application to the case of the ports of Pakistan. Marit. Econ. Logist. 2010, 12, 237-262. [CrossRef]

34. Kaysi, I.; Nehme, N. Optimal investment strategy in a container terminal: A game theoretic approach. Marit. Econ. Logist. 2016, 18, 250-263. [CrossRef]

35. Khanizad, R.; Montazer, G. Participation against competition in banking markets based on cooperative game theory. J. Financ. Data Sci. 2018, 4, 16-28. [CrossRef]

36. Álvarez, X.; Gómez-Rúa, M.; Vidal-Puga, J. River flooding risk prevention: A cooperative game theory approach. J. Environ. Manag. 2019, 248, 109284. [CrossRef]

37. Csercsik, D.; Hubert, F.; Sziklai, B.R.; Kóczy, L.Á. Modeling transfer profits as externalities in a cooperative game-theoretic model of natural gas networks. Energy Econ. 2019, 80, 355-365. [CrossRef]

38. Song, D.P.; Lyons, A.; Li, D.; Sharifi, H. Modeling port competition from a transport chain perspective. Transp. Res. Part E Logist. Transp. Rev. 2016, 87, 75-96. [CrossRef]

39. Talley, W.K.; Ng, M.W. Port economic cost functions: A service perspective. Transp. Res. Part E Logist. Transp. Rev. 2016, 88, 1-10. [CrossRef]

40. Chang, Y.T.; Park, H.K.; Lee, S.; Kim, E. Have emission control areas (ecas) harmed port efficiency in europe? Transp. Res. Part D Transp. Environ. 2018, 58, 39-53. [CrossRef]

41. Fan, K.; Hui, E.C.M. Evolutionary game theory analysis for understanding the decision-making mechanisms of governments and developers on green building incentives. Build. Environ. 2020,179, 106972. [CrossRef] 
42. Wan, X.L.; Qie, X.Q. Poverty alleviation ecosystem evolutionary game on smart supply chain platform under the government financial platform incentive mechanism. J. Comput. Appl. Math. 2020, 372, 112595. [CrossRef]

43. Nielsen, I.E.; Majumder, S.; Sana, S.S.; Saha, S. Comparative analysis of government incentives and game structures on single and two-period green supply chain. J. Clean. Prod. 2019, 235, 1371-1398. [CrossRef]

44. Xi, X.; Zhang, J. Complexity analysis of a decision-making game concerning governments and heterogeneous agricultural enterprises with bounded rationality. Chaos Solitons Fractals 2020, 140, 110220. [CrossRef]

45. Jiang, B.; Wang, X.; Xue, H.; Li, J.; Gong, Y. An evolutionary game model analysis on emission control areas in China. Mar. Policy 2020, 118, 104010. [CrossRef]

46. Gao, X.; Shen, J.; He, W.; Sun, F.; Zhang, Z.; Guo, W.; Zhang, X.; Kong, Y. An evolutionary game analysis of governments' decision-making behaviors and factors influencing watershed ecological compensation in china. J. Environ. Manag. 2019, 251, 109592. [CrossRef]

47. Friedman, D. Evolutionary Games in Economics. Econometrica 1991, 59, 637-666. [CrossRef]

48. Zhang, M.; Li, H.; Xue, L.; Wang, W. Using three-sided dynamic game model to study regional cooperative governance of haze pollution in China from a government heterogeneity perspective. Sci. Total Environ. 2019, 12, 694. [CrossRef]

49. Zhang, N.; Zhang, X.; Yang, Y. The behavior mechanism of the urban joint distribution alliance under government supervision from the perspective of sustainable development. Sustainability 2019, 11, 6232. [CrossRef]

(C) 2020 by the authors. Licensee MDPI, Basel, Switzerland. This article is an open access article distributed under the terms and conditions of the Creative Commons Attribution (CC BY) license (http://creativecommons.org/licenses/by/4.0/). 